\title{
Knowledge Design and Illusions/Delusions of Agency
}

JOHANNA DRUCKER ${ }^{1}$

1. Inaugural Breslauer Professor of Bibliographical Studies, Department of Information Studies, University of California at Los Angeles, Los Angeles, CA, USA

SUGGESTED CITATION: Drucker, J. “Knowledge Design and Illusions/Delusions of Agency.” Dialectic, 1.2 (2017): pgs. 6-12. DOI: http://dx.doi.org/10.3998/dialectic.14932326.0001.201

\section{Abstract}

This article addresses the challenges for design pedagogy in supplying the intellectual and critical skills for knowledge design in networked projects. In addition to the need for technical understanding (of data formats, infrastructure, and information systems), this piece suggests that a critical understanding of the concepts of agency should also be part of the designer's skill set. Every model of design practice contains an idea of the designer's agency - as an autonomous, free-willed individual, a part of a social system, an agent for transformative change, an interventionary force, an instrument of resistance, etc. In turn, the designed environment encodes illusions of agency for a user. The ability to articulate these critical dimensions and understand one's role in the supply chain of illusion is an essential aspect of design practice. Preparing designers for this role should be a crucial component of design education.

\section{Keywords}

agency, illusion, delusion, design

pedagogy, interface 


\section{Knowledge Design and Illusions /}

\section{Delusions of Agency}

JOHANNA DRUCKER

Challenges for the pedagogy of graphic design have expanded in recent decades as designers have taken on the complexities of working with information systems. The design of web interfaces depends on understanding data formats, computational processing, content management, and a host of other technical aspects of working in a networked environment. So, the question arises - what does a designer need to know to be part of the field of knowledge design?

Anne Burdick's exemplary work on the Die Fackel (The Torch) project provides a useful answer. ${ }^{1}$ Burdick designed a multi-faceted interface for an online repository of the full 37-year run of a journal edited from 1899-1936 by the renowned early 2oth-century writer, Karl Kraus. Linguists at the Austrian Academy of Sciences had spent twenty-plus years in extensive analysis and mark-up (tagging) of the scanned, transcribed, and much-studied influential texts. An enormous investment had been made in creating digitized versions of the journal, preparing it for use before it went online. Burdick's interface design enables access to the complex set of cultural materials so that transcriptions, facsimiles, keyword searches and other features are coordinated in a manner that seems intuitive to the user. Burdick's interface demonstrates a precise understanding of the organization of these components and their relation to the scholarly tasks to which they would be put. To make these interlocking components legible and effectively accessible and usable, she had to be able to understand them conceptually, even if she did not herself build the content management systems within which these components were designed to function. Intellectual skill, not technical know-how, was key to doing this effectively, but the willingness to engage with and understand the working features of this particular technical infrastructure was essential.

The interface hides the workings of the technological apparatus, which, after all, the user does not need to see or know about (most scholars have as little interest in or use for understanding the information architecture of online repositories as for the design of shelving and classification systems in analogue libraries). But the research environment creates a platform that allows Kraus's critical point of view, and his sharp focus on exposing the ideological workings of cultural systems (especially language), to be studied in a manner that matches its intellectual content (every word can be tracked and studied in context). In its current academic environment, the repository inevitably participates in institutional circumstances that are squarely within what Louis Althusser termed

\footnotetext{
The Die Fackel site requires registration and login, but is free to use: http://corpus1.aac ac.at/fackel/ (Accessed 6/28/2017).
} 


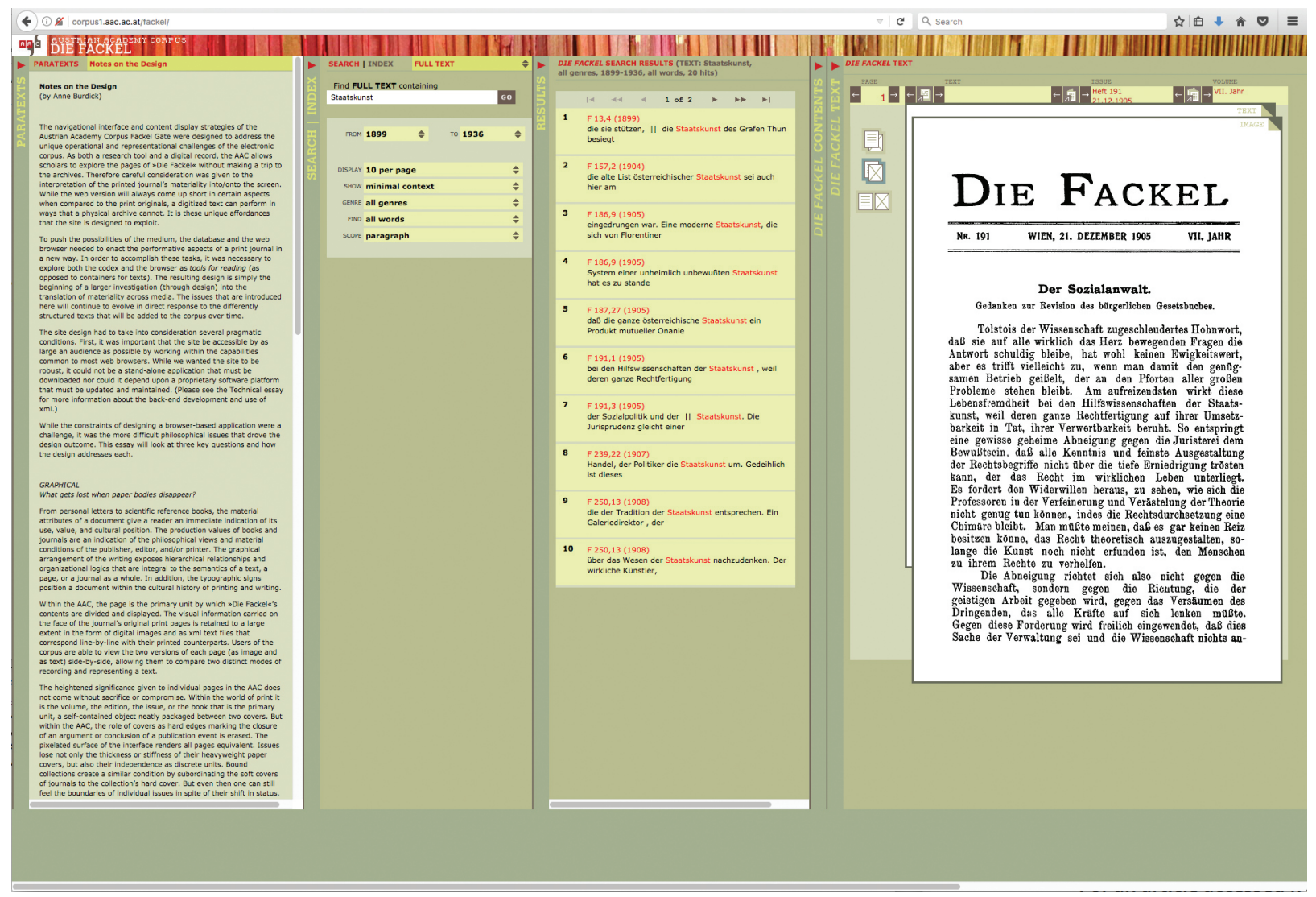

ABOVE: Die Facke/ website, designed by Anne Burdick.

the "ideological state apparatus," but that fact is neither obscure nor concealed. ${ }^{2}$

As an example of knowledge design, Burdick's work tells us that current pedagogy has to prepare designers to understand these information systems. The functionality of a given interface depends upon that understanding. This adds a new suite of skills to the designer's toolkit. But is that all that is required? What intellectual tools for understanding the ideological aspects of this work are also needed? How does design - whether in traditional graphic and print modes, or in dynamic environments - produce models of agency that become part of other cultural practices? What notions of the user - or subject - are assumed in these activities, and how do we provide the critical language for understanding the ideological conditions created by our work? Burdick's Die Fackel project was done in the context of digital humanities. The design serves scholarly purposes that support the study of language in Austria during the rise of fascism (the journal was published continuously from 1899 to 1936). Because of this, the implications of these historical circumstances can be studied for analysis of other cultural moments, such as our own.

Not all interfaces are the same, and the knowledge design skills necessary for a humanities' project are not those needed for integrating live data streams in a complex business or government environment. For instance, interfaces built on platforms that use the metaphors of dashboard and cockpit as the control centers for access encode very different illusions of control than those of digital humanities projects and provide a useful contrast. Recent work by Miriam Posner calls attention to the structure of supply chains in manufacturing. She studies the way business management software makes use of neural, net-based artificial intelligence to optimize the efficient delivery of goods, labor, raw materials, services, and every other aspect of production in the

2 Althusser, L. "Ideology and the Ideological State Apparatus." In Lenin and Philosophy and Other Essays, translated by Brewster, B. New York, NY, USA: Monthly Review Press, 1971. 
manufacture and distribution of consumer products from t-shirts to private jets. The interfaces designed for these circumstances are deliberately obfuscating in their operation. They track availability of components for a final product (including services like transportation, assembly, mining etc.), but they do not expose any of the causes for breakdowns and delays, or any of the human, ecological, or political costs of the components. Instead, these types of interfaces provide a nice, clean, seamless surface view. Behind the screen, the system is constantly updating itself to heal breaks and repair damage in these supply chains, directing a decision-making process that bypasses the effects of social crises, natural cataclysms, labor abuses, and so on.

As design educators, scholars and researchers, our pedagogical challenges are ethical as well as aesthetic, intellectual and technological. How do we conceive these ethical dimensions and on what grounds do we posit the agency of either design or designers to intervene or play a role of any kind in the cultural systems within which we are all working — and with which we are all complicit? To answer this question, let's review the ways in which our understanding of the relation between design and agency has changed — and how different models of design practice create illusions and delusions of agency.

A century and a half ago, the term "design agency" clearly designated an organization of professionals who offered their services to do something-promote a product or a brand through a combination of identity campaigns and publicity. N.W. Ayer, founded in Philadelphia in 1869, is the paradigmatic early example of design in the service of commerce and consumption. Agency was understood as the capacity to be effective. In our contemporary moment, concepts of agency have been informed by new materialist approaches that split sentential agency (a self-aware cognition) from mechanical agency. A driver deciding to run over a pedestrian is exercising sentential agency, while a rock burying that car in a landslide is likely operating with mechanical agency. A third concept of agency - performative agency-describes the ability of a work, word person, or object to make something happen through an action or expression. A judge pronouncing a sentence exercises performative agency. Agency is also constrained by chains of command or authority within the structure of businesses and institutions - the degree of free will or autonomy varies considerably, as does the way we internalize our options.

Every approach to design education assumes a model of agency - the power of the designer to do something persuasive, transformative, interventionary - whether wittingly or not. Early examples of design pedagogy were almost indistinguishable from apprenticeship to the printing trade. From the publication of Joseph Moxon's Mechanick Exercises in the late 17th century until more than two hundred years later, the role of design was barely separated from that of craft. Instruction manuals for printers might carry a few paragraphs on pleasing composition or the judicious selection of fonts, but no specific discussion of design as a field appeared until the turn of the 2oth century. Walter Crane's Line and Form, published in 1900 and much influenced by the politics and

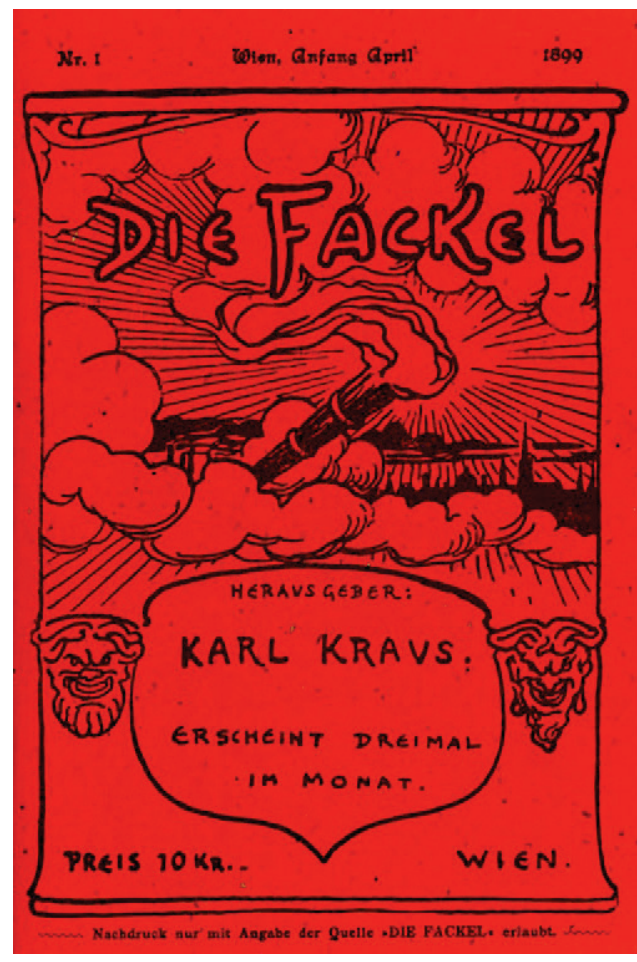

ABOVE: Book cover Die Fackel (The Torch), by Karl Kraus, 1899, Wien. 
aesthetics of William Morris, combined the craft aesthetic with utopian aspirations for social progress. For Crane, the designer/artist was part of a guild of progressive thinkers drawing on deeply humanistic values, hoping to redress the ills of industrialization. His model of agency assumed an autonomous, self-determined subject uncomplicated by awareness of their complicity with the hegemonic systems of which they were a part, but motivated by the (at the time still rare) conviction that social responsibility was essential on professional as well as personal levels. Morris and Crane's designer would make a better world - and make the world better - by design.

The Bauhaus curriculum (and similar approaches in the Soviet and Dutch contexts in the 1920 s and 1930s) offered a dramatic breakthrough in thinking about design as a set of formal principles that could be articulated and taught. Here the model of design agency was that of a self-aware constructor, rational and mechanistic (in a positive sense), making use of a universal approach that could produce consistent results. Gestalt principles and psychological studies of perception described the visual impact of these designed objects. But these orientations paid little attention to the kinds of manipulative techniques in public relations being developed in the service of social engineering. Edward Bernays, the nephew of Sigmund Freud, was a pioneer in this domain, and his work in the 1920 s established the force of transformative agency in shaping public opinion. The contrast between his campaigns to encourage suffragettes to smoke cigarettes and El Lissitzky's attempts to guide Soviet workers towards utopian agendas through the development of a radically innovative graphic language is telling. Lissitzky's belief in the capacity of design to create radical transformation was never realized - but social engineering shapes our daily lives. The overt force of marketing campaigns and messaging in the promotion of everything from bottled water (as a necessity for good health) to political candidates (as likely fatal) is obvious. But the more subtle practices of agenda-setting and formation of public opinion through the use of words, images, and associations are a direct legacy of Bernays' techniques.
By the mid-2oth-century, designers were fully cognizant of their ability to create desire for products through lifestyle imagery or advertising that took advantage of fantasy, anxiety, or fears of inadequacy. This model of manipulative agency was exposed in critical work by Vance Packard (Hidden Persuaders, 1957), Marshall McLuhan (The Mechanical Bride, 1951), and others even as the rise of corporate design (exemplified in the heroic posturing of Paul Rand and others) legitimated a model of instrumental efficacy. Corporate systems, like those of supply chains, mask the workings of large-scale enterprises through a unified and monolithic brand. Designers who participate in this illusion of "success" as an unproblematically positive model, suffer their own delusion - a belief in their autonomous agency within a system whose fuller workings they do not see-or that they choose to ignore.

The critical awareness expressed in Ken Garland's group-authored "First Things First" manifesto (1964) was a clear attempt at modeling agency deliberately, imbued with social awareness of the designer's role. Very much a part of 1960s' activist sensibility, the manifesto suggested a designer could elect the ethical high road in decisions about the use of his or her skills and talent. In the same era, the wink-wink sly cleverness of design practices worked to engage consumers in an in-the-know insider sense of their own awareness of the game (think of Doyle, Dane and Bernbach). But these design tactics contain their own features of delusion, promoting mainstream consumption with counter-culture style. The same insider skills operationalized in the service of effective slogans and campaigns to protest the Vietnam war produced an esoteric brand of discriminating taste. The capacity for building social movements promoted the designer's self-perception of political agency — even as those talents were applied in the service of mass consumption. The complicity of designers was in part masked by the idea of effective agency.

Post-modern design was influenced by critical theory and cultural studies and dissolution of the autonomous humanistic subject. Embracing fragmentary identity and the 
production of meaning across signs, it promoted a concept of agency as constructed, situated, contingent - but stylish and very hip. By the 1980s, hipster activism - the "fair trade" approach to agency — suggested that making certain choices over others was sufficient to guarantee moral superiority. Important contributions to the counter-discourse became highly visible — for instance, Adbusters, founded in 1989 and/or Naomi Klein's influential 1999 work, No Logo). ${ }^{3}$ In cultural politics, the agency of identity became linked to rules about who was/is allowed to say what to whom under certain - various - circumstances.

The current proliferation of activist and participatory websites and the design of social media model a user empowered with an illusion of transformative power. The design of these interfaces often promotes a click-and-participate illusion of democracy. Simon Penny's useful formulation of "inter-passivity" instead of "inter-activity" makes the point that the design of networked environments is frequently based on menu-driven options, not generative actions. In keeping with Ben Shneiderman's mantra of "overview first, zoom, and details," such a user is a consuming subject, one situated within fully designed systems, rather than a producing subject with power and agency.

What is it we imagine design can do? We are all caught in the snares and tangles of our own ideological conditions. Our notions of agency - autonomous, sentient, free-willed —or abject, constrained, subordinated_inform (literally, shape, give form to) our models of design. Activist design and resistant action are essential components of our current world, but naïve concepts of effective agency are not. The historical development of design into a field with activist and political agendas was built on models of a humanist subject with full political efficacy, along with the direct capacity for action. But agency has to be understood as a product, an idea constructed from and within the cultural systems that "speak" to us as subjects of complex regimes of power.

3 Adbusters, edited by Lasn, K. \& Schmalz, B. Founded 1989; Vancouver, B.C., Canada, and Klein, N. No Logo. Toronto, Canada: Knopf Canada and Pickador, 1999.

\section{We are most deluded when we are most convinced of our capacity for agency.}

Design education has included awareness of the ideological complexities of cultural practices for more than a century. But we do not always call out the explicit assumptions built into imagining the role of the designer and the model of agency we attribute to it. For instance, the assumption that design functions in the service of human communication-shaping an expression in the relation of one person or business to another-no longer holds. We return to the contrast between Burdick's interface to a cultural repository and Posner's analysis of supply chain software. At work in the latter are intelligent systems that do not consult with their human operators - even if they were originally designed by individual human beings to produce legible, efficient, presentations of information on screen. The business software described by Posner is meant to create an illusion of control, and to fully mask the ideological conditions of cycles of production and consumption - and their human, ecological, and political costs.

We are now positioned within complex systems whose machinations can hardly, barely, be intervened through individual agency. In these contexts, what is the role of design? We are all complicit with the supply chain of delusion in which we are caught, trapped, and produced as cultural subjects - but acknowledging that and having the language to engage in analysis is still a crucial component of all education. Knowledge design must be premised on critical principles and awareness of the illusions and delusions of the agency it engages and produces if it is to help us survive.

Johanna Drucker; the Breslauer Professor of Bibliographical Studies at UCLA, is internationally known for her work in the history of graphic design, typography, experimental poetry, fine art, and digital humanities. Recent publications include What Is? (Cuneiform Press, 2013), Graphesis: Visual Forms of 
KNOWLEDGE DESIGN AND ILLUSIONS/DELUSIONS OF AGENCY

Knowledge Production (Harvard University Press, 2014), and

Digital Humanities, co-authored with Anne Burdick, Peter Lunenfeld, Todd Presner, and Jeffrey Schnapp, (MIT Press, 2012). In 2012, Drucker's creative work was the subject of a retrospective, Druckworks: 40 years of books and projects. She is working on a database memoire, ALL the books I never wrote or wrote and never published. Recent projects include Diagrammatic Writing (Onomatopée, 2014), Stochastic Poetics (Granary, 2012), and Fabulas Feminae (Litmus Press, 2015). In 2014, she was elected to the American Academy of Arts and Sciences, and she was awarded an honorary doctorate of Fine Arts by the Maryland Institute College of Art in 2017. 